\title{
Influences on Interdisciplinary Collaboration Among Social Work and Health Sciences Students
}

\author{
Sang Jung Lee \\ Stacey L. Shipe
}

\begin{abstract}
Interdisciplinary collaboration is an effective and satisfying way to provide health care services and learning across professions. This study aimed to explore interdisciplinary collaboration experiences amongst social work and allied health sciences graduate students and examined factors that contributed to their interdisciplinary collaboration. An interdisciplinary survey was conducted in a MidAtlantic public university. Analysis was conducted using hierarchical regressions from 112 health sciences and social work students. Students with positive attitudes toward interdisciplinary health care teams and part-time students compared to fulltime students presented higher flexibility of interdisciplinary collaboration. Students with positive experiences of interdisciplinary collaboration demonstrated higher levels of interdependence, compared to those with no and negative experiences of interdisciplinary collaboration. Students in medicine were less likely to show interdependence, compared to those in social work. Professional disciplines and educators should put efforts in offering opportunities for interdisciplinary collaboration practice and building curricula to promote positive attitudes toward interdisciplinary teamwork.
\end{abstract}

Keywords: Social work, allied health sciences, interdisciplinary collaboration

Interdisciplinary collaboration is an effective and satisfying way to provide health care services (Drotar, 2002; Hanson, Spross, \& Carr, 2000; Robinson \& Kish, 2001). But it is also important for solving complex and multidimensional issues in health and human services (Mabry, Olster, Morgan, \& Abrams, 2008; Syme, 2008). In social work practice and health care settings, serving clients effectively is impossible without collaboration with professionals from other disciplines (Bronstein, 2003). Therefore, health care and health education decision-makers have been more attuned to education and professional collaboration across disciplines (Reeves et al., 2011).

Current research has shown that interdisciplinary education improved the skills and behaviors that are needed for effective interdisciplinary collaboration both academically and professionally (Barr, 2002; Curran, Sharpe, Forristall, \& Flynn, 2008; Meads \& Ashcroft, 2005). Ivey, Brown, Teske, and Silverman (1988) found that undergraduate students exposed to an interdisciplinary course would be more likely to work collaboratively once they moved into the workforce. Among professionals, Gaboury, Bujold, Boon, and Moher (2009) found that practitioners were more likely to collaborate with clinicians who had been exposed to interdisciplinary collaboration trainings.

These positive findings have also been replicated in studies focusing specifically on social workers. For the better part of 100 years the pairing of social workers and allied health care professionals (e.g., nursing and medicine) has been common practice as the social worker can help to provide a broader perspective on patient health (Baldwin, 2000). Consequently, social workers in both academic and

Sang Jung Lee, MSW, and Stacey L. Shipe, MSW, MSc, are both PhD students in the University of Maryland School of Social Work in Baltimore, MD.

Copyright (C) 2014 Advances in Social Work Vol. 15 No. 2 (Fall 2014), 352-367 
professional settings are more likely to have positive attitudes about collaboration (Carpenter, 2002; Peterson et al., 1998).

Due to the research on the benefits of interdisciplinary collaboration experiences, particularly in professional settings, the opportunity for students to obtain interdisciplinary training should be a priority (Kenaszchuk, Rykhoff, Collins, McPhail, \& van Soeren, 2012). Many institutions of higher education have started offering interdisciplinary courses and programs that support the development of student interdisciplinary collaboration (Browne et al., 1995). However, there is still little opportunity for students to understand the values, roles, and expertise of other health professionals (Clark, 1997; Irvine, Kerridge, McPhee, \& Freeman, 2002). This has led to students entering interdisciplinary settings where traditional roles, responsibilities, and territory from their own disciplines are maintained $(\mathrm{Mu}, \mathrm{Chao}$, Jensen, \& Royeen, 2004).

Thus, this study aimed to explore interdisciplinary collaboration amongst social work and allied health sciences graduate students and to examine factors that contribute to their interdisciplinary collaboration. Findings will provide implications for educating and preparing students to work in social work and allied health sciences.

\section{Literature Review}

Of the studies that focused on interdisciplinary collaboration, the populations typically came from either a professional or college setting. Studies in a college setting had a focus on the implementation of a new class or curriculum. The studies also tended to target undergraduate students rather than those students focusing on specific career tracks (Browne et al., 1995; Chan, Chi, Ching, \& Lam, 2010; Curran, Sharpe, Flynn, \& Button, 2010; Misra et al., 2009). On the other hand, studies from professional settings tended to focus on policy changes or environmental moves (Burd et al., 2002; Liedtka \& Whitten, 1998). Despite these differences in the population settings, there were a number of similar findings, including exposure to interdisciplinary collaborations as well as intrinsic and extrinsic characteristics, including chosen discipline.

\section{Previous Interdisciplinary Collaboration Experiences}

Studies focused on interdisciplinary trainings or courses in college have reported improved outcomes relating to interdisciplinary collaboration. Interdisciplinary trainings improved students' understanding of professional role, responsibilities, and interdisciplinary behavior such as teamwork and communication skills (Amundson, Moulton, Zimmerman, \& Johnson, 2008; Misra et al., 2009). Similarly, Browne et al. (1995) found that in an integrated ethics course among allied health professions all the participants enjoyed the course and found the exposure to other professions to enhance their understanding of decision making and confidentiality. Misra and colleagues (2009) further found that students who were exposed to an interdisciplinary training were more likely to engage in interdisciplinary behaviors and activities as compared to students who did not receive the training; these findings were consistent among the 101 training participants.

Very little research has been conducted on the association between past interdisciplinary work experience and future interdisciplinary collaboration. With this knowledge, Bronstein (2002) predicted that social work professionals with previous 
interdisciplinary experiences (paid or unpaid) would be more likely to continue working in an interdisciplinary environment; however, she found that this hypothesis supported only for those in unpaid or internship work settings. In another study, Bronstein (2002) found that a professional who had a positive collaboration experience continued to have positive attitudes about professional collaboration.

\section{Individual Characteristics}

Among the studies that examined individual characteristics that supported interdisciplinary collaborations, Liedtka and Whitten (1998) found that a commitment to the process of collaborating was a critical determinant in developing trust and open communication among the different disciplines. Burd et al. (2002) also concluded that strong communication skills among professionals were crucial for collaborative relationship development; however, Gaboury et al. (2009) reported that not only was open communication necessary but also how the information was communicated, such as in a face to face manner versus in passing, affected collaboration outcomes. Participants found that having dedicated time to discuss cases and pertinent health care topics increased collaboration. Overall, when a person was able to communicate his or her needs, the boundaries, and mission of the profession, the group would become more cohesive and would demonstrate more positive attitudes about interdisciplinary collaborations (Gaboury et al., 2009; Misra et al., 2009).

\section{Disciplinary Culture}

Although research has mainly reported on the usefulness of interdisciplinary collaborations, many disciplines promote a perspective that directly opposes this rationale and supports the tendency to maintain professional territories (D'Amour, Sicotte, \& Levy, 1999). This can also be found when interpreting a professional's code of ethics. Whereas social work, nursing, and public health all explicitly mention the need to collaborate with other professions in order to maximize knowledge and skills of other professions as it relates to patient outcomes, medicine and pharmacy do not state that there is a need to collaborate unless it benefits the patient (American Medical Association, 2001; American Nurses Association, 2001; American Pharmaceutical Association, 1994; National Association of Social Workers, 2008; Public Health Leadership Society, 2002).

Of the studies that examined the effect of collaborating among different disciplines, many found that type of discipline affected how they perceived other professions (Curran, Health, Kearney, \& Button, 2010; Gaboury et al., 2009; Rijnsoever \& Hessels, 2011; Stone, Ekman, English, \& Fujimori, 2008). Leipzig et al. (2002) found that medical residents held significantly less positive attitudes toward interdisciplinary collaboration than did students in social work and nursing. Similar findings were reported in the study by Curran, Sharpe, and colleagues (2010) where medical students showed more negative attitude toward interdisciplinary healthcare team and pharmacy students reported more positive attitudes during three-year interdisciplinary education curricula than three disciplines (medicine, nursing, and social work). Conversely, Rijnsoever and Hessels (2011) found that students in fields with practical application of interdisciplinary techniques, such as medicine or other helping professions, were more likely to want to collaborate with other disciplines. What these studies suggest is that students from different disciplines demonstrate diverse attitudes toward interdisciplinary collaboration. 
Studies that focused on social workers found that most had a positive perception of interdisciplinary collaboration; however, some findings illuminated that beneath the positive perception were consistent concerns around having their voice heard and attempting to navigate non-social work paradigms (Chan et al., 2010; Jani, Tice, \& Wiseman, 2012; Mizrahi \& Abramson, 2000; Parker-Oliver \& Peck, 2006). For example, in the study conducted by Parker-Oliver and Peck (2006), social work hospice workers found that having professionals from other disciplines with whom to discuss cases and obtain different perspectives was helpful when dealing with difficult issues. On the other hand, rigidity on the use of the medical model prevented social workers from being able to work with patients outside of physical complaints. Similarly, Mizrahi and Abramson (2000) found that social workers viewed the professional collaboration with physicians as benefitting the patient but that the physicians did not view the social workers' skills as contributing as much as their own to the case.

Various professional and educational contextual factors can influence participants' interdisciplinary collaboration and the experience of collaboration can promote future interdisciplinary collaborations. However, many of the studies reviewed above used qualitative or experimental study designs; thus, multiple factors that are associated students' interdisciplinary collaboration could not be examined simultaneously. Therefore, using a cross-sectional design, this study examined factors associated with interdisciplinary collaboration through the following research question: "what factors are predictive of interdisciplinary collaboration among graduate students in social work and allied health science?"

\section{Conceptual Framework}

Bronstein's (2003) interdisciplinary collaboration model guided the current study. The model was built upon the multidisciplinary theory of collaboration, services integration, role theory, and ecological systems theory and was aimed at social work practitioners (Bronstein, 2003). According to the model, interdisciplinary collaboration consists of interdependence, newly created professional activities, flexibility, collective ownership of goals, and a reflection process. However, this study sampled both students in social work as well as those in allied health fields. Thus, only the flexibility and interdependence constructs were used because they are applicable to all the professions included in this study. Flexibility is defined as deliberately blurring roles so compromises can be made; and interdependence means the occurrence of reliance on interactions amongst professionals from different disciplines (Bronstein, 2003).

Bronstein (2003) identified four major influences on the interdisciplinary collaboration model including professional role, structural and personal characteristics, and history of collaboration. Professional role refers to how a profession socializes its members according to role type, values, and practice (Abramson, 1990). How interdisciplinary relationships are built is also contingent upon one's professional role (i.e., type of discipline and role type). Structural characteristics refer to an organization's desire and ability to foster interdisciplinary collaboration. For example, many academic settings offer interdisciplinary courses and programs which are meant to enhance a student's professional training (Browne et al., 1995). Personal characteristics center on how collaborators view each other above and beyond their professional role such as trust, respect, understanding, and 
informal communication (Mattessich \& Monsey, 1992), while history of collaboration is about a person's past experiences with interdisciplinary collaboration.

Applying the Bronstein (2003) interdisciplinary collaboration model to this study, the four aforementioned influencers are operationalized in the following manner: for professional role, we focused on the differences between social work, medicine, nursing, and other allied health sciences including dentistry, pharmacy, and public health among students in a graduate setting. Structural characteristics were defined as the number of interdisciplinary courses that students have taken. Although this definition does not directly parallel Bronstein's, it was chosen based on the assumption that a school desiring to foster interdisciplinary collaboration among students would offer more courses with this mission thus allowing students to take them. For example, PhD students in the School of Social Work, where this study was conducted, must take a course outside the School in order to graduate.

Personal characteristics were defined as a student's attitudes toward interdisciplinary collaboration health care teams. Finally, personal/professional history of collaboration was operationalized as past experience in interdisciplinary teams (e.g., as practicums, internships, or part-time/full-time jobs). The study model is presented in Figure 1.

Figure 1. Influences on Interdisciplinary Collaboration Applying Bronstein's Model (2003)

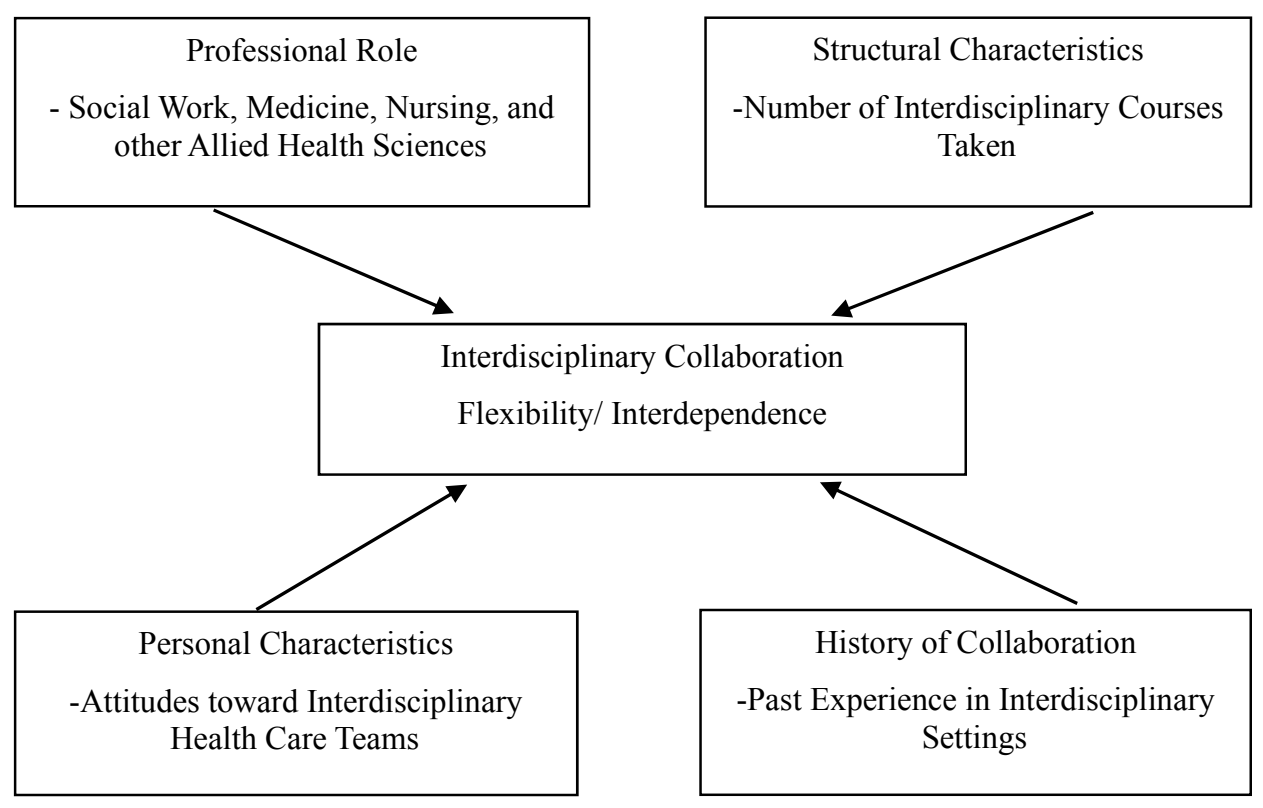

\section{Method}

\section{Research Procedure}

This study used a cross-sectional design with a non-probability convenience sample of students enrolled in a Mid-Atlantic public university. Institutional Review Board (IRB) approval was obtained in August 2012. The university is made up of 
seven schools (medicine, nursing, pharmacy, social work, dental, law and graduate) with degrees predominantly at the graduate level. The survey, Interprofessional Students Interdisciplinary Survey (ISIS), was sent out in two waves, two weeks apart by the university's student government association, which has access to the email addresses of all enrolled students,. The online survey used Qualtrics software (Qualtrics, Provo, UT) to gather data from study participants.

\section{Sample}

All students $(N=6,368)$ who were enrolled for the fall semester of 2012 automatically received the ISIS through their school email. A total of 288 surveys were completed yielding a response rate of $4.5 \%$. Due to this study's interest in health sciences students currently working on an interdisciplinary practice, 176 students were excluded (students not currently working; $n=172$, students in non-health sciences disciplines such as law; $n=14$ ). This resulted in a total sample of 112 .

\section{Measures}

Dependent variables. Perceived flexibility and interdependence of interdisciplinary collaboration were measured using the two subscales from the Index of Interdisciplinary Collaboration (IIC; Bronstein, 2002). All items were rated on a five-point Likert scale and summed for total scores. Higher scores indicate a higher level of flexibility and interdependence. Interdependence scale consisted of 12 items and flexibility consisted of 6 items. Parker-Oliver, Bronstein, and Kurzejeski (2005) reported a Chronbach's alpha of .78 for reliability of the interdependence scale and .62 for the flexibility scale. The present study produced a Cronbach's alpha values of .74 for interdependence and .59 for flexibility.

Independent variables. A student's school affiliation was used to indicate their professional role. Students were categorized into four groups depending on their affiliation: social work, nursing, medicine, and other allied health sciences (pharmacy, dental, and public health). Social work was used as a reference group. The number of interdisciplinary courses that a student had taken ranged from 0 to $5+$ and was continuous.

To assess students' experience with interdisciplinary collaboration, two questions from the ISIS were used: (1) have you ever worked as part of a team with professionals from other disciplines? (Yes/No); and (2) was your overall experience positive or negative? The responses ranged from very negative (1 point) to very positive (5 points). Students were coded into two groups: those who answered with no to the first question, and those who negative, very negative, and neither negative nor positive to the second question were coded as 1 , whereas students that had positive or very positive experiences were coded as 0 .

The last independent variable used a standardized instrument, students' Attitudes Towards Interdisciplinary Health Care Teams, originally developed by Heinemann, Schmitt, Farrell, and Brallier (1999). It consists of 14 five-point Likert scale items ranging from strongly disagree (1 point) to strongly agree (5 points). The total score ranges from 14 to 70, and higher scores indicate more positive attitudes. Reliability of the Attitudes Towards Interdisciplinary Health Care Teams scale has been supported by previous studies; Heinemann et al. (1999) and Curran et al. (2008) each reported a Cronbach's alpha of .83 , and this study also demonstrated a high reliability of the 
scale $(a=.88)$. Total scores were used to indicate students' attitudes toward interdisciplinary health care teams for this study.

Demographic variables. Age, race, and attendance status (part or full time) were included in the model as control variables. Age was measured at a continuous level. Race was dummy-coded to compare Whites with Non-Whites. Part-time students were compared to full-time students. Female students were compared to male students.

\section{Data Analysis}

Statistical Software for the Social Sciences (SPSS v.18, 2010) was used for data analysis. Following descriptive and bivariate analyses of variables of interest, a hierarchical multiple regression was used to determine which factors predict graduate students' positive experience of interdisciplinary collaboration. Listwise deletion was employed for missing data which removed 8 cases $(7.7 \%)$ yielding a final sample size of 104. Continuous variables were normally distributed based on their skewness and kurtosis.

\section{Results}

\section{Descriptive and Preliminary Analyses}

The results of descriptive statistics are presented in Table 1. Among the study participants, allied health sciences students were evenly distributed (social work: $n=$ 32; 28.6\%, nursing: $n=32 ; 28.6 \%$, medicine: $n=18 ; 16.1 \%$, and other allied health sciences: $n=30 ; 26.8 \%)$. Nearly two-thirds $(n=73 ; 67.6 \%)$ were White, and more than two-thirds were full-time students $(n=82 ; 73.2 \%)$. The majority of students had positive past experience of interdisciplinary collaboration $(n=95 ; 84.8 \%)$. Students' mean age was $32.54(S D=10.45$, Range: $22-59)$.

Students took $1.81(S D=1.94$, Range: $0-5)$ interdisciplinary courses on average. On average, students scored $21.96(S D=2.84$, Range: $13-30)$ in flexibility and 46 $(S D=5.18$, Range: $31-60)$ in interdependence. Gender was associated with students' disciplines $\left(X^{2}(1)=5.78 ; p=.02\right)$; meaning male students were more likely to be affiliated with allied health science disciplines versus social work. There were no other significant differences between Social Work and allied health sciences students in bivariate analyses.

\section{Hierarchical Multiple Regressions}

Two separate hierarchical multiple regression analyses were conducted to examine factors that predict students' flexibility and interdependence of interdisciplinary collaboration. Hierarchical multiple regression analysis allows one to evaluate the unique contributions of the model variables after accounting for control variables. The assumptions for multiple regression analysis (normality of residuals, independence of residuals, linearity, homoscedasticity of residuals, and non-multicollinearity) were checked and met. In step 1, individual characteristics including age, gender, and student status were entered to be controlled. Four model variables (disciplines, the number of interdisciplinary courses taken, attitudes toward interdisciplinary healthcare teams, and past experience in interdisciplinary settings) 
were entered in step 2 to examine changes in variance and coefficients. The results of the hierarchical regressions are presented in Table 2.

Table 1. Descriptive Statistics

\begin{tabular}{|c|c|c|c|c|c|}
\hline Variable & Valid $N$ & Range & M & & SD \\
\hline Flexibility & 112 & $13-30$ & 21.96 & & 2.84 \\
\hline Interdependence & 112 & $31-60$ & 46.00 & & 5.18 \\
\hline Number of courses & 109 & $0-5$ & 1.81 & & 1.94 \\
\hline ATIHT $^{\mathrm{a}}$ & 110 & $3.21-5$ & 3.93 & & .35 \\
\hline Age & 112 & $22-59$ & 32.54 & & 10.45 \\
\hline Variable & \multicolumn{2}{|r|}{$N$} & \multicolumn{3}{|c|}{$(\%)$} \\
\hline \multicolumn{6}{|l|}{ Gender $(N=110)$} \\
\hline Female & \multicolumn{2}{|r|}{97} & \multicolumn{3}{|c|}{88.2} \\
\hline Male & \multicolumn{2}{|r|}{13} & \multicolumn{3}{|c|}{11.8} \\
\hline \multicolumn{6}{|l|}{ Race $(N=108)$} \\
\hline White & \multicolumn{2}{|r|}{73} & \multicolumn{3}{|c|}{67.6} \\
\hline Non-White & \multicolumn{2}{|r|}{35} & \multicolumn{3}{|c|}{32.4} \\
\hline \multicolumn{6}{|l|}{ Attendance status $(N=112)$} \\
\hline Part-time & \multicolumn{2}{|r|}{30} & \multicolumn{3}{|c|}{26.8} \\
\hline Full-time & \multicolumn{2}{|r|}{82} & \multicolumn{3}{|c|}{73.2} \\
\hline \multicolumn{6}{|l|}{ Discipline $(N=112)$} \\
\hline Social Work & \multicolumn{2}{|r|}{32} & \multicolumn{3}{|c|}{28.6} \\
\hline Medicine & \multicolumn{2}{|r|}{18} & \multicolumn{3}{|c|}{16.1} \\
\hline Nursing & \multicolumn{2}{|r|}{32} & \multicolumn{3}{|c|}{28.6} \\
\hline Other allied health sciences & \multicolumn{2}{|r|}{30} & \multicolumn{3}{|c|}{26.8} \\
\hline \multicolumn{6}{|l|}{ Past experience $(N=112)$} \\
\hline Positive experience & \multicolumn{2}{|r|}{95} & \multicolumn{3}{|c|}{84.8} \\
\hline No \& negative experience & \multicolumn{2}{|r|}{17} & \multicolumn{3}{|c|}{15.2} \\
\hline
\end{tabular}

Note ${ }^{\mathrm{a}}$ : Attitudes toward Interdisciplinary Health Care Teams Scale 
Table 2. Results of Hierarchical Multiple Regressions

\begin{tabular}{|c|c|c|c|c|c|c|c|c|c|c|c|c|}
\hline \multirow[b]{2}{*}{ Model } & \multirow[b]{2}{*}{$R^{2}$} & \multirow[b]{2}{*}{$R^{2} \Delta$} & \multicolumn{3}{|c|}{ Flexibility } & \multirow[b]{2}{*}{$95 \% \mathrm{CI}$} & \multirow[b]{2}{*}{$R^{2}$} & \multirow[b]{2}{*}{$R^{2} \Delta$} & \multicolumn{2}{|c|}{ Interdependence } & \multirow[b]{2}{*}{$\beta$} & \multirow[b]{2}{*}{$95 \%$ CI } \\
\hline & & & $\mathrm{B}$ & S.E. & $\beta$ & & & & $\mathrm{B}$ & S.E. & & \\
\hline Step 1 & $.18^{* *}$ & & & & & & $.20^{* * *}$ & & & & & \\
\hline Age & & & $.06^{*}$ & .03 & $.21^{*}$ & $.01, .12$ & & & $.15^{* *}$ & .05 & $.29^{* *}$ & $.05, .25$ \\
\hline $\begin{array}{l}\text { Gender } \\
\text { (Male) }\end{array}$ & & & -.74 & .80 & -.09 & $-2.31, .84$ & & & -1.74 & 1.40 & -.11 & $-4.51,1.04$ \\
\hline $\begin{array}{l}\text { Race } \\
\quad \text { (Non-White) }\end{array}$ & & & .65 & .57 & .10 & $-.49,1.78$ & & & .69 & 1.01 & .06 & $-1.30,2.69$ \\
\hline $\begin{array}{l}\text { Attendance status } \\
\text { (Part-time) }\end{array}$ & & & $-1.76^{* *}$ & .65 & $-.27^{* *}$ & $-3.04,-.48$ & & & $-2.67^{*}$ & 1.14 & $-.23^{*}$ & $-4.92,-.42$ \\
\hline Constant & & & $20.88^{* * *}$ & 1.30 & & $18.31,23.45$ & & & $42.65^{* * *}$ & 2.28 & & $38.13,47.17$ \\
\hline Step 2 & $.32^{* * *}$ & $.14^{* *}$ & & & & & $.43^{* * *}$ & $.23^{* * *}$ & & & & \\
\hline Age & & & .03 & .03 & .11 & $-.02, .09$ & & & .08 & .05 & .16 & $-.01, .17$ \\
\hline $\begin{array}{l}\text { Gender } \\
\text { (Male) }\end{array}$ & & & .07 & .81 & .01 & $-1.53,1.67$ & & & -.69 & 1.32 & -.04 & $-3.31,1.94$ \\
\hline $\begin{array}{l}\text { Race } \\
\quad \text { (Non-White) }\end{array}$ & & & .39 & .56 & .06 & $-.72,1.50$ & & & .47 & .92 & .04 & $-1.36,2.30$ \\
\hline $\begin{array}{l}\text { Attendance status } \\
\text { (Part-time) }\end{array}$ & & & $-1.49^{*}$ & .69 & $-.23^{*}$ & $-2.86,-.12$ & & & -1.13 & 1.13 & -.10 & $-3.38,1.11$ \\
\hline Medicine (SW) & & & -.11 & .81 & -.01 & $-1.71,1.49$ & & & $-3.42^{*}$ & 1.32 & $-.25^{*}$ & $-6.05,-.80$ \\
\hline Nursing (SW) & & & 1.14 & .74 & .18 & $-.33,2.61$ & & & 2.18 & 1.21 & .19 & $-.23,4.59$ \\
\hline $\begin{array}{l}\text { Other health disciplines } \\
\text { (SW) }\end{array}$ & & & -.82 & .72 & -.13 & $-2.25, .61$ & & & -1.20 & 1.18 & -.10 & $-3.55,1.14$ \\
\hline $\begin{array}{l}\text { Past experience } \\
\quad \text { (Positive experience) }\end{array}$ & & & -.78 & .70 & -.10 & $-2.17, .61$ & & & $-4.35^{* * *}$ & 1.15 & $-.31^{* * *}$ & $-6.63,-2.07$ \\
\hline N. of courses & & & .01 & .02 & .06 & $-.02, .04$ & & & .01 & .03 & .02 & $-.05, .06$ \\
\hline ATIHT $^{\mathrm{a}}$ & & & $1.79^{*}$ & .79 & $.22^{*}$ & $.22,3.34$ & & & -.38 & 1.30 & -.03 & $-3.00,3.21$ \\
\hline Constant & & & $14.74^{* * *}$ & 3.35 & & $8.08,21.40$ & & & $46.34^{* * *}$ & 5.50 & & $35.41,57.26$ \\
\hline
\end{tabular}

Note ${ }^{\mathrm{a}}$ : Attitudes toward Interdisciplinary Health Care Teams scale, ( ): reference, SW: Social Work, ${ }^{*} p<.05,{ }^{* *} p<.01,{ }^{* * *} p<.001$ 
The first regression analysis examined predictors of flexibility. Demographic variables were entered instep 1 of the model, explaining $18 \%$ of the variance $\left(F_{(4,99)}=\right.$ $5.43, p=.001)$. For one unit increase in age, flexibility increased .06 points $(B=.06, t$ $=2.19, p=.03)$ independent of the other variables. Attendance status was also a significant predictor of flexibility at the first step $(B=-1.76, t=-2.73, p=.008)$; fulltime students' scores in flexibility were 1.76 points lower than those of part-time students, holding all other variables constant.

Interdisciplinary collaboration model variables were entered in step 2 of the model, increasing the model $R^{2}$ significantly to $.32\left(R^{2} \Delta=.14, F_{(10,93)}=4.45, p<.001\right)$. Attendance status remained significant $(B=-1.49, t=-2.17, p=.03)$. In addition, among the model variables, attitudes toward interdisciplinary health care teams $(B=$ $1.79, t=2.26, p=.03$ ) significantly predicted students' flexibility of interdisciplinary collaboration. For each one unit increase in attitudes toward interdisciplinary health care teams, flexibility of interdisciplinary collaboration increased 1.79 points, holding all other variables constant.

The second regression analysis examined predictors of interdependence. Demographic variables were entered in step 1 of the model; $20.1 \%$ of variance was explained $\left(F_{(4,99)}=6.23, p<.001\right)$. Attendance status $(B=-2.67, t=-2.35, p=.02)$ and age $(B=.15, t=3.04, p=.003)$ were the significant predictors of interdependence. Interdisciplinary collaboration model variables were entered in step 2 of the model, increasing the model $R^{2}$ significantly to $.43\left(R^{2} \Delta=.23, F_{(10,93)}=6.92, p<.001\right)$. Attendance status and age did not remain significant. However, compared to students in social work, those in medicine were less likely to demonstrate interdependence, taking the other factors into account $(B=-3.42, t=-2.59, p=.01)$. In addition, past experience significantly predicted interdependence of interdisciplinary collaboration ( $B=-4.35, t=-3.79, p<.001)$; compared to students with positive experience, those with no and negative experience scored 4.35 points lower in interdependence, controlling for all other variables. The other three interdisciplinary collaboration model variables were not statistically significant.

\section{Discussion}

This study examined factors that influenced graduate students' interdisciplinary collaboration based on Bronstein's (2003) interdisciplinary collaboration model. This model was developed to conceptualize collaboration between social workers and other professionals in practice. The results of this study suggested that Bronstein's (2003) model emphasizing the importance of individual and environmental factors predicting interdisciplinary collaboration holds not just for seasoned professionals but for students being socialized to their professions. Bronstein (2002) originally tested her model with professionals; however, subsequent research with college students (Bronstein, 2003; Parker-Oliver et al., 2005), including this study, has shown that the model applies to this population as well.

Positive attitudes towards collaboration are indicative of successful interdisciplinary collaboration (Browne et al., 1995; Gaboury et al., 2009). Research has also shown that health sciences students and professionals generally reported positive attitudes toward interdisciplinary teamwork or education (Curran et al., 2008; Curran, Sharpe, et al., 2010). This study found that when students had more positive attitudes toward interdisciplinary health care teams, they were more likely to show 
higher levels of flexibility of interdisciplinary collaboration. Studies have shown that students and practitioners with exposure to interdisciplinary courses or trainings were more likely to collaborate with others from different disciplines (Gaboury et al., 2009; Ivey et al., 1988). Therefore, in order to foster positive attitudes toward interdisciplinary collaboration, educators and professions should offer more interdisciplinary classes and training opportunities to students.

Students in social work and allied health sciences who had a positive experience of interdisciplinary collaboration in the past were more likely to rely on interactions with professionals from different disciplines than were those who had no or negative experience. This result is consistent with previous studies that demonstrated that positive experiences in interdisciplinary settings were associated with interdisciplinary collaboration (Amundson et al., 2008; Bronstein, 2002). This finding underscores the importance of disciplinary curricula that necessarily include interdisciplinary collaboration. Headrick and Khaleel (2008) suggested that involving trainees from one profession to work with other health professionals as their mentors or teachers enriched the student experience as did a well-developed interdisciplinary practicum course that involved students and/or faculty members from other disciplines. In addition, as Amundson et al. (2008) suggested, interdisciplinary student internship programs are a way to expose health sciences students to interdisciplinary collaboration.

Among the control variables, attendance status significantly predicted both flexibility and interdependence of interdisciplinary collaboration. It even significantly predicted flexibility controlling for other factors; part-time students showed higher levels of flexibility than full-time students. Because part-time students are more likely to be working than full-time students, they could have more exposure to interdisciplinary collaboration practice. This is in line with findings from Rijnsoever and Hessels (2011) who found that previous work experiences influenced current interdisciplinary collaborations. Along with the positive past experience, this emphasized the importance of practice experience among students during their learning process to help influence future interdisciplinary collaboration. The significant positive relationship between age and interdependence also emphasized the importance of collaboration experience. Older students were more likely to have come from settings where interdisciplinary collaboration was either part of their practice or their many years of experience has provided evidence for the usefulness of IDC.

The study finding that students in medicine were less likely to demonstrate interdependence compared to those in social work was consistent with the finding of previous studies where medical students reported significantly less positive attitudes toward interdisciplinary collaboration (Curran, Heath, et al., 2010; Leipzig et al., 2002). However, there was no other significant difference found in flexibility and interdependence compared to social work. The approach of social work to clients (i.e., understanding a client in the context of his or her environment and helping the client function appropriately in the context) is distinct from that of other health care professions (Gitterman \& Heller, 2011). The non-significant findings on flexibility and interdependence may be due to the academic environment where this study was conducted; the university emphasizes the importance of interdisciplinary collaboration and provides opportunities for interdisciplinary collaboration across all disciplines. Another possible reason could be that students' school affiliation may not 
have captured their professional roles in the interdisciplinary settings. Assessment of each profession's expected or valued role in interdisciplinary collaboration settings, with a validated measure, may produce more reliable study results.

The number of interdisciplinary courses taken was not a significant predictor of either flexibility or interdependence. The number of interdisciplinary courses taken may have been a limited measure to assess disciplines' structural characteristics, although more interdisciplinary courses would be available for students when schools value and support interdisciplinary collaboration across professions. Each discipline's educational policy or level of administrative support toward interdisciplinary collaboration may be a more accurate construct to measure disciplines' structural characteristics.

Limitations of this study should be acknowledged. Online surveys usually result in a lower response rate than mail (paper) surveys (Nulty, 2008; Resnick, 2012) or inperson surveys (Truell, Barlett, \& Alexander, 2002); it is possible that the low response rate $(4.5 \%)$ of this study also may have been due to use of the online survey. However, the low response rate may not represent the school population. In addition, small sample size may limit generalizability of the study findings, although post-hoc tests, using $\mathrm{G}^{*}$ Power 3.1, suggested that the sample size provided enough power for the statistical analyses for interdependence (99.9\%) and flexibility (95.7\%). Therefore, the results of this study may not be generalizable to all graduate students within the university or students within and among the different schools. Second, technical problems that were caused by the use of online survey (e.g. not receiving emails, not being able to open the survey) as well as the anonymous nature of the survey could have led to biased responses. Third, for the purpose of the survey applying to students from all available disciplines, three constructs of the Interdisciplinary Collaboration model (Bronstein, 2003; newly created professional activities, collective ownership of goals, and a reflection process) were not measured in this study. These constructs should be investigated in the future because they could offer a more comprehensive lens of student perceptions. In addition, the accepted norm of internal reliability of a scale is .70 (Huey et al., 2004). However, the reliability of the flexibility subscale was below the norm, although previous studies also reported the lower internal reliability (Bronstein, 2002; Parker-Oliver et al., 2005); therefore, results based upon the flexibility subscale should be interpreted with caution.

\section{Implications for Research}

Despite the limitations, this study has important implications for future studies and for allied health sciences and social work students' education. Few studies have explored interdisciplinary collaboration among student groups. Moreover, quantitative studies that used a cross-sectional design and examined factors of interdisciplinary collaboration among allied health sciences and social work students are rarely found. This study can be used as a foundation that leads to more quantitative research on this student group's interdisciplinary collaboration.

\section{Implications for Interdisciplinary Education}

This study suggests that the future direction of interdisciplinary education is to foster allied health sciences and social work students as competent collaborators. Graduate school administrators and educators should offer opportunities for 
interdisciplinary collaboration practice experience. Educators and students in these disciplines should put effort into promoting positive attitudes toward interdisciplinary teamwork through interdisciplinary trainings and courses as means of the professional development process. When students have positive experiences with interdisciplinary collaboration during their learning process, they will be more open to collaborating with other professionals and the collaboration will contribute to better client and patient outcomes.

\section{References}

Abramson, J. S. (1990). Making teams work. Social Work with Groups, 12(4), 45-62.

American Medical Association. (2001). Code of Medical Ethics. Retrieved from http://www.ama-assn.org/ama/pub/physician-resources/medical-ethics/codemedical-ethics.page

American Nurses Association. (2001). Code of Ethics for Nurses. Retrieved from http://www.nursingworld.org/mainmenucategories/ethicsstandards/codeofethicsfo rnurses/code-of-ethics.pdf

American Pharmaceutical Association. (1994). Code of Ethics for Pharmacists. Retrieved from http://www.pharmacist.com/code-ethics

Amundson, M. L., Moulton, P. L., Zimmerman, S. S., \& Johnson, B. J. (2008). An innovative approach to student internships on American Indian reservations. Journal of Interdisciplinary Care, 22(1), 93-101.

Barr, H. (2002). Interdisciplinary education: Today, yesterday and tomorrow. London: Health Sciences and Practice, Learning and Teaching Support Network. Retrieved from http://78.158.56.101/archive/health/doc/mp/0103 hughbarr.pdf/at_download/file.pdf

Baldwin, M. (2000). Care management and community care: Social work discretion and the construction of policy. Burlington, VT: Ashgate.

Bronstein, L. R. (2002). Index of interdisciplinary collaboration. Social Work Research, 26(2), 113-123.

Bronstein, L. R. (2003). A model for interdisciplinary collaboration. Social Work, 48, 297-306.

Browne, A., Carpenter, C., Cooledge, C., Drover, G., Ericksen, J., Fielding, D.,...Sweeny, V. (1995). Bridging the professions: An integrated and interdisciplinary approach to teaching health care ethics. Academic Medicine, 70(11), 1002-1005.

Burd, A., Cheung, K. W., Ho, W. S., Wong, T. W., Ying, S. Y., \& Cheng, P. H. (2002), Before the paradigm shift: concepts and communication between doctors and nurses in a burns team. Burns, 28, 691-695.

Carpenter, J. (2002). Mental health recovery paradigm: Implications for social work. Health \& Social Work, 27(2), 86-94.

Chan, A. C., Chi, S. P. M, Ching, S., \& Lam, S. (2010). Interprofessional education: The interface of nursing and social work. Journal of Clinical Nursing, 19(1-2), $168-176$. 
Clark, A. (1997) Being there: Putting brain, body and world together again. Cambridge, MA: MIT Press.

Curran, V. R., Heath, O., Kearney, A., \& Button, P. (2010). Evaluation of an interprofessional collaboration workshop for post-graduate residents, nursing and allied health professionals. Journal of Interdisciplinary Care, 24(3), 315-318.

Curran, V., Sharpe, D., Flynn, K., \& Button, P. (2010). A longitudinal study of the effect of an interdisciplinary education curriculum on student satisfaction and attitudes towards interdisciplinary teamwork and education. Journal of Interdisciplinary Care, 24(1), 41-52.

Curran, V., Sharpe, D., Forristall, J., \& Flynn, K. (2008). Student satisfaction and perceptions of small group process in case-based interdisciplinary learning. Medical Teacher, 30, 431-433.

D'Amour, D., Sicotte, C., \& Levy, R. (1999). L'action collective au sein d'équipes interprofessionnelles dans les services de santé. Sciences Sociales et Santé, 17(3), 67-94.

Drotar, D. (2002). Reflections on interdisciplinary collaboration in the new millennium: Perspectives and challenges. Journal of Developmental \& Behavioral Pediatrics, 23(3), 175-180.

Gaboury, I., Bujold, M., Boon, H., \& Moher, D. (2009). Interdisciplinary collaboration within Canadian integrative health care clinics: Key components. Social Science \& Medicine, 69, 707-715.

Gitterman, A., \& Heller, N. R. (2011). Integrating social work perspectives and models with concepts, methods and skills with other professions' specialized approaches. Clinical Social Work Journal, 39, 204-2011. doi:10.1007/s10615011-0340-7

Hanson, C. M., Spross, J. A., \& Carr, D. B. (2000). Collaboration. In A. B. Hamric, J. A. Spross, \& C. M. Hanson (Eds.), Advanced practice nursing: An integrative approach ( $2^{\text {nd }}$ ed., pp. 315-347). Philadelphia, PA: W. B. Saunders.

Headrick, L. A., \& Khaleel, N. I. (2008). Getting it right: Educating professionals to work together in improving health and heal care. Journal of Interdisciplinary Care, 22(4), 364-374.

Heinmann, G., Schmitt, M. H., Farrell, M. P., \& Brallier, S. A. (1999). Development of an attitudes toward Health Care Teams Scale. Evaluations \& the Health Professions, 22, 123-142. doi:10.1177/01632789922034202

Huey, S., Henggeler, S. W., Rowland, M. D., Halliday-Boykins, C. A., Cunningham, P. B., Pickrel, S. G., \& Edward, J. (2004). Multisystemic therapy effects on attempted suicide by youths presenting psychiatric emergencies. Psychiatry, 43(2), 183-190.

Irvine, R., Kerridge, I., McPhee, J., \& Freeman, S. (2002). Interprofessionalism and ethics: Consensus or clash of cultures? Journal of Interprofessional Care, 16(3), 199-210.

Ivey, S. L., Brown, K. S., Teske, Y., \& Silverman, D. (1988). About interdisciplinary practice in health care settings. Journal of Allied Health, 17, 189-195. 
Jani, J. S., Tice, C., \& Wiseman, R. (2012). Assessing an interdisciplinary health care model: The Governor's Wellmobile Program. Social Work in Health Care, 51(5), 441-456.

Kenaszchuk, C., Rykhoff, M., Collins, L., McPhail, S., \& van Soeren, M. (2012). Positive and null effects of interprofessional education on attitudes toward interprofessional learning and collaboration. Advances in Health Sciences Education, 17(5), 651-669.

Leipzig, R. M., Hyer, K., Ek, J., Wallenstein, S., Vezina, M. L., Fairchild, S.,...Howe, J. L. (2002). Attitudes toward working on interdisciplinary healthcare teams: A comparison by discipline. Journal of the American Geriatrics Society, 50, 11411148 .

Liedtka, J. M., \& Whitten, E. (1998). Enhancing care delivery through crossdisciplinary collaboration: A case study. Journal of Healthcare Management, 43(2), 185-203.

Mabry, P. L., Olster, D. H., Morgan, G. D., \& Abrams, D. B. (2008). Interdisciplinarity and systems science to improve population health: A view from the NIH Office of Behavioral and Social Science Research. American Journal of Preventive Medicine, 35(2), S211-S224.

Mattessich, P., \& Monsey. B. (1992). Collaboration: What makes it work. St. Paul, $\mathrm{MN}$ : Amherst H. Wilder Foundation.

Meads, G., \& Ashcroft, J. (2005). Collaboration. In G. Meads, \& J. Ashcroft; with H. Barr, R. Scott, \& A. Wild (Eds.), The case for interdisciplinary collaboration in health and social care (pp. 15-35). Oxford: Blackwell Publishing Ltd.

Misra, S., Harvey, R. H., Stokols, D., Pine, K. H., Fuqua, J., Shokair, S. M., \& Whiteley, J. M. (2009). Evaluating an interdisciplinary undergraduate training program in health promotion research. Journal of Preventive Medicine, 36(4), 358-365.

Mizrahi, T., \& Abramson, J. (2000). Collaboration between social workers and physicians: Perspectives on a shared case. Social Work in Health Care, 31(3), 124.

Mu, K., Chao, C. C., Jensen, G. M., \& Royeen, C. B. (2004). Effects of interprofessional rural training on students' perceptions of interprofessional health care services. Journal of Allied Health, 33(2), 125-131.

National Association of Social Workers. (2008). Code of Ethics of the National Association of Social Workers. Retrieved from http://www.socialworkers.org/pubs/code/code.asp

Nulty, D. D., (2008). The adequacy of response rates to online and paper surveys: What can be done? Assessment \& Evaluation in Higher Education, 33(3), 301314.

Parker-Oliver, D., Bronstein, L., \& Kurzejeski, L. (2005). Examining variables related to successful collaboration on the hospice team. Health and Social Work, 30(4), 279-286. 
Parker-Oliver, D., \& Peck, M. (2006). Inside the interdisciplinary team experiences of hospice social workers. Journal of Social Work in End of Life and Palliative Care, 2(3), 7-21.

Peterson, B. D., West, J., Tanielian, T. L., Pincus, H. A., Kohout, J., Pion, G. M.,...Manderscheid, R. W. (1998). Mental health practitioners and trainees. In R. W. Manderscheid \& M. J. Henderson (Eds.), Mental health, United States, 1998 (U.S. DHHS Pub. No. 99-3285, pp. 214-245). Washington, DC: U.S. Government Printing Office. Retrieved from http://www.nursing.virginia.edu/media/1998\%20Mental\%20HealthUS\%20\%20Chap $\% 2017 \% 20$ Mental\%20Health\%20Practitioners\%20and $\% 20$ Trai nees.pdf

Public Health Leadership Society. (2002). Principals of the ethical practice of public health. Retrieved from http://phls.org/CMSuploads/Principles-of-the-EthicalPractice-of-PH-Version-2.2-68496.pdf

Reeves, S., Goldman, J., Gilbert, J., Tepper, J., Silver, I., Suter, E., \& Zwarenstein, M. (2011). A scoping review to improve conceptual clarity of interdisciplinary intervention. Journal of Interdisciplinary Care, 25(3), 167-174. doi: $10.3109 / 13561820.2010 .529960$

Resnick, R. M., (2012). Comparison of postal and online surveys: Cost, speed, response rates and reliability. 2012 Education Market Research and MCH Strategic Data. Retrieved from http://mchdata.com/collateral/whitepapers/Comparison-of-Postal-and-Online-Surveys.pdf

Rijnsoever, F. J., \& Hessels, L. K. (2011). Factors associated with disciplinary and interdisciplinary research collaboration. Research Policy, 40, 463-472.

Robinson, D., \& Kish, C. P. (2001). Core concepts in advanced practice nursing. St. Louis, MO: Mosby.

Stone, S., Ekman, E., English, D., \& Fujimori, S. (2008). Collaboration among social work and journalism students and faculty: An instructional model. Journal of Social Work Education, 44(1), 163-172.

Syme, S. L. (2008). The science of team science. Assessing the value of transdisciplinary research. American Journal of Preventive Medicine, 35(2S), S94-S95.

Truell, A. D., Barlett, J. E., \& Alexander, M. W. (2002). Response rate, speed, and completeness: A comparison of Internet-based and mail surveys. Behavior Research Methods, Instruments, \& Computers, 34(1), 46-49.

\section{Author note}

Address correspondence to: Sang Jung Lee, MSW, University of Maryland School of Social Work, 525 West Redwood Street Suite 502 SSW/LAW Building, Baltimore, MD 21201. Email: $\underline{\text { slee@ssw.umaryland.edu }}$ 